\title{
Epidemiological aspects of gastric adenocarcinoma: are predictive diagnostics and targeted preventive measures possible?
}

\author{
Krister Sjödahl • Jesper Lagergren
}

Received: 22 April 2010 /Accepted: 5 July 2010 /Published online: 22 July 2010

(C) European Association for Predictive, Preventive and Personalised Medicine 2010

\begin{abstract}
The incidence of gastric cancer has witnessed major changes over the past decades. Until recently, gastric cancer was a common malignancy in most countries. A striking decline in incidence in most Western populations has occurred since the 1970s, and elucidating the detailed causes for this trend can potentially be of great value for targeted preventive measures. Furthermore, it can add to the understanding of malignant disease and prevention in general. Moreover, the absolute number of cases worldwide is predicted to increase during many years to come. Gastric cancer is typically diagnosed at an advanced stage in symptomatic patients, and there are often no effective curative or palliative or therapeutic options. This fact highlights the need for research aiming to increase our understanding of the etiology of this cancer, facilitating the design of successful targeted preventive strategies for different populations. The future outlook in terms of decreasing gastric cancer deaths would be to identify such intelligent diagnostic tools. In this article, we present a summary of the epidemiology of gastric cancer, with special focus on its etiology.
\end{abstract}

Keywords Predictive $\cdot$ Preventive $\cdot$ Personalized medicine . Neoplasm · Adenocarcinoma · Stomach · Risk factor . Epidemiology

K. Sjödahl $(\bowtie) \cdot$ J. Lagergren

Upper Gastrointestinal Research,

Department of Molecular Medicine and Surgery,

Karolinska Institutet, Karolinska University Hospital,

Norra Stationsgatan 67, 2 tr,

SE-171 76 Stockholm, Sweden

e-mail: krister.sjodahl@ki.se

\section{Introduction}

In recent years, etiological research concerning gastric cancer has been dominated by the role of the bacteria Helicobacter pylori (H. pylori). About half of the world's population is infected with this bacteria, and it is becoming increasingly clear that also other environmental factors are of critical importance in gastric cancer causation, such as cigarette smoking, diet, and gastroesophageal reflux. The risk might be influenced both through interaction with this bacterium and by affecting the risk independently.

\section{Gastric cancer incidence}

Gastric adenocarcinoma is currently the fourth most common malignancy globally and the second leading cause of cancer-related death [1]. Only cancer of the lung, breast, and colon are more common. It has been estimated that 934,000 new cases of gastric cancer occur every year, and that 700,000 people die annually from this disease [1], representing more than $10 \%$ of all cancer deaths. Two thirds of the patients live in developing countries. There has been a marked fall in its incidence in developed countries since the 1930s, which has been described as one of the greatest medical triumphs of the last century. The development reflects a change in incidence rather than earlier diagnosis, better treatment, or changes in definition [2]. The authors of a recent study concluded that steady downward trends in gastric cancer mortality worldwide have continued during the last decades [3]. However, as a consequence of the aging and growing global population, it is predicted that the absolute number of gastric cancer cases will continue to increase up to the year $2050[2,4]$. Gastric cancer is closely associated with age, the peak incidence being between the 
5th and 7th decades of life. There is an overall male predominance, with 2-3 males per every female affected, but the declining incidence has occurred in both sexes. However, increased attention has been directed to what seems to be an increasing trend in incidence of cancer in the gastric cardia. Classification of tumors of the proximal stomach is potentially unreliable and clinicians might use different definitions when reporting to cancer registries, but the acceleration in the incidence of cardia cancer seems to be real [5]. A widely used system of classification was proposed by Siewert in 1998 [6]. For cardia cancer, there is an even more pronounced male to female ratio, around $6: 1$, and this cancer is more common among whites and in Western countries [7-9]. These striking epidemiological patterns are still only partly explained. Elucidation of modifiable causes of these trends could potentially lead to an acceleration of the decline in the incidence of non-cardia gastric cancer, as well as a reverse of the opposite incidence trend regarding cardia cancer.

Globally, there is a 10 -fold variation in reported national incidence rates of gastric cancer [1]. However, underestimation from less developed parts of the world where health care availability, diagnostic methods, and cancer reporting practices exhibit shortcomings render valid comparisons difficult. High incidences of gastric cancer have been noted in Japan, South Korea, Central and South America, and Eastern Europe, while low incidence rates have been reported from parts of East Asia, Scandinavia, Western Europe, North America, Australia, and regions in Africa. In 2002, the worldwide average estimate of age-adjusted incidence was 22.0 per 100,000 person-years in men and 10.3 per 100,000 person-years in women [1]. In many populations, the decline in incidence of gastric cancer has followed a birth-cohort phenomenon, i.e. the incidence rate in subsequent generations tend to fall, implying shared temporal risk factors [10].

\section{Histology of gastric cancer}

Adenocarcinomas represent more than $95 \%$ of gastric neoplasms. Other types include stroma cell tumors (GIST), lymphomas, lipomas, carcinoids, adenomas, and metastases. Laurén suggested that gastric adenocarcinoma cases should be divided into two histologically distinct groups: 1) the intestinal type, with glandular epithelium composed of absorptive cells and goblet cells, and 2) the diffuse type, with poorly differentiated small cells in a dissociated noncohesive growth pattern $[11,12]$. In addition, mixed tumors occur, representing a combination of the intestinal and diffuse types $[12,13]$. The intestinal type is more common than the diffuse type in areas with a high incidence of the disease [14].
There are marked clinical and genetic differences regarding the two histological types of gastric adenocarcinoma, and much evidence supports the possibility of separate disease etiologies $[2,15]$. However, no clear-cut differences in the pattern of risk factors have been revealed in studies where the two histological types of gastric cancer have been analyzed separately [16-18]. A wide range of genetic and epigenetic abnormalities, including point mutation, loss of heterozygosity, microsatellite instability, and hypermethylation, are described in the intestinal type and its precursor lesions [19]. The diffuse type is characterized by absence of such pre-neoplastic lesions, and mutation or epigenetic silencing of the E-cadherin gene seems to be an important carcinogenic event $[19,20]$. Furthermore, the diffuse type is more frequent in younger individuals and has a more equal male-to-female ratio [12]. Much of the decline in the incidence of gastric cancer seems to be the result of a falling rate of new cases of the intestinal type. A classical hypothesis regarding the pathogenesis defining the intestinal type was presented in 1975 by Correa et al. [21]. According to this suggestion, which has been slightly changed during the years, the development of gastric cancer follows the sequence: $H$. pylori-superficial gastritis-atrophic gastritis-intestinal/ complete metaplasia - colonic/incomplete metaplasia-dysplasia-carcinoma [21, 22]. The progression of these lesions follows a pattern of steady state, with episodes of progression to more advanced lesions, and episodes of regression to less advanced lesions. Gastric atrophy leads to loss of parietal cells and hyposecretion of gastric acid, in turn leading to an increased $\mathrm{pH}$ of the gastric juice, facilitating proliferation of anaerobic bacteria which reduce nitrate to nitrite, abundant in many foods. From nitrite, carcinogenic N-nitrosamines can be generated. Reducing agents such as ascorbic acid prevents the formation of nitrosated and nitrated compounds [23]. Intramucosal production of carcinogenic nitrosamines has also been suggested [24]. There have been concerns that widespread treatment with proton pump inhibitors could lead to an increase in gastric cancer $[25,26]$, since such therapy causes corpus-dominant gastritis in patients with $H$. pylori infection which is associated with hyposecretion [27]. However, there is no strong support for such an adverse effect of proton pump inhibitors [28].

It is quite possible that the intestinal type of cancer arises in a gastric mucosa that has undergone a sequence of mutations and histopathological changes that may have started in the first decades of life. Although the exact mechanisms leading to neoplastic transformation remain largely unknown, focus has been directed to the possibility that "oxidative stress" might be crucial in the carcinogenic process $[29,30]$. This implicitly suggests that counteractive "antioxidant" measures could protect the DNA of the 
mucosal cells from a continuous barrage of genotoxic agents. Recently, intriguing evidence that bone marrowderived stem cells are involved in gastric cancer development has become available [31, 32]. Peripheral tissue stem cells in the gastric mucosa might be damaged by chronic inflammation [31]. This in turn leads to the recruitment and permanent engraftment of bone marrow-derived stem cells into the tissue stem cell niche. With ongoing inflammation and injury these cells are exposed to an abnormal tissue environment characterized by elevated cytokine and growth factor levels which are likely to initiate differentiation, but fail to regulate growth programs appropriately and instead progress through stages of metaplasia and dysplasia [31, 32].

\section{Etiology of gastric cancer}

Environmental factors are of greater importance than genetic factors in gastric cancer etiology [15]. Familial clustering of cases does occur, suggesting a prominent genetic causal role in some cases, but exposures other than hereditary generally play a more decisive role in the population at large. Supporting these findings is the observation that first generation migrants from highincidence areas sustain the risk of their country of origin but that the incidence rate in subsequent generations falls [33]. This pattern is also seen, for example, for colon cancer, but in the case of gastric cancer this adaptation seems to be slower. These observations strengthen the hypothesis that factors acting early in life could have a very important role in gastric carcinogenesis.

Older age is linked with increased risk. In this context it is a proxy for degenerative changes and accumulated DNA damage. In addition, gastric cancer occurs predominantly in lower socioeconomic groups. This inverse relation with socioeconomic status is observed in almost every population $[34,35]$, but there is no exact correlation to the national level of economic development [1].

\section{Genetic causes}

Some $10 \%$ of patients with gastric cancer have a family history of this disease, and there is a slightly greater disease correlation between identical rather than fraternal twins [36]. Nevertheless, many genes that underlie inherited cancer syndromes have a more widespread role in sporadic cancers, as a result of somatic mutations that arise during tumor initiation or progression [20]. The discovery of germ line mutation at the E-Cadherin gene, coding for a celladhesion protein, in familial gastric cancers of the diffuse histological subtype, is an example of progressing understanding of gastric cancer genetics. It has also been shown that expression of E-Cadherin decreases along Correa's cascade [37], and that $H$. pylori infection is associated with down regulation of E-Cadherin $[38,39]$. Other studies have shown intriguing associations between polymorphisms in genes coding for pro-inflammatory cytokines and risk of gastric cancer [40]. Mutations in the Interleukin-1B gene have been considered to be among the most crucial, although a recent meta-analysis did not provide any support for such an association [41].

\section{Helicobacter pylori}

The Nobel Prize in Physiology or Medicine in 2005 was awarded to the Australian physicians Barry J. Marshall and J. Robin Warren "for their discovery of the bacterium Helicobacter pylori and its role in gastritis and peptic ulcer disease" [42]. This remarkable discovery was made in 1983, and since then it has become increasingly clear that this bacterium also plays a prominent causative role in the etiology of gastric cancer. In 1994, IARC classified $H$. pylori as a definite class 1 carcinogen [43]. As conflicting results accumulated, some scientists came to believe that this decision was made somewhat prematurely, but added together, the results obtained over the last 20 years strongly indicate that $H$. pylori plays a true causal role in gastric cancer etiology [44-46]. The average strength of the relation as determined by meta-analyses produces an effect size of about a doubled risk [47-49]. H. pylori infection has been found in human stomachs all over the world. Most infections seem to be acquired in childhood, typically lasting for many decades or for lifetime [50]. The mode of transmission is not completely understood, but the fecaloral bacterial transmission route is probably the most important [51]. Approximately half of the global population is infected, and the occurrence is strongly correlated with low socioeconomic status [52]. In some low-income countries, $70-90 \%$ of the inhabitants are infected, whereas in high-income countries, the prevalence is $25-50 \%$. $H$. pylori infection is associated with an inflammation of the gastric mucosa. The exact mechanisms by which this bacterium causes gastric cancer remain to be elucidated [53], but the clinical outcome of this infection is determined by an interplay between $H$. pylori, host derived factors, and environmental factors [32]. In some areas of the world a very high prevalence of $H$. pylori infection runs parallel with low gastric cancer rates [54]. Many bacterial virulence factors that might play a role in $H$. pylori related disease outcomes have been identified. Cytotoxin associated gene A (CagA) positive strains are, for example, associated with a further increased risk of gastric adenocarcinoma [53]. In the Western countries, around $60 \%$ of $H$. pylori isolates possess CagA, compared to virtually all isolates in Japan [55]. As a result of polymorphisms coding for this virulence 
factor, populations infected with East Asian CagA-positive strains may be at an especially great risk for gastric cancer [56]. However, antibodies against CagA seem to persist longer in serum than conventionally used antibodies utilized for bacterial detection. This could partly explain the stronger observed association between CagA positive strains and gastric cancer [57, 58]. A strong, but ineffective, immune response is typically associated with $H$. pylori infection. Genetic polymorphisms influence individual variation in the extent and pattern of cytokine response, and thus seem to contribute to the clinical outcome of the individual [59]. It has been proposed that environmental factors and host related factors may be more important than H. pylori virulence factors in producing gastric cancer [60]. In line with this suggestion is the observation of a rapid change in the worldwide incidence of this malignancy. This could potentially be explained by a similar decrease in the prevalence of a particular bacterial virulence factor, but there is evidence against this hypothesis [61]. H. pylori can be diagnosed by a variety of tests and is readily treated with antibiotics, and recent findings from a Japanese randomized study showing that gastric cancer rates are substantially reduced, but not abolished, by $H$. pylori eradication have intensified the debate of preventive eradication [62]. There are still no preventive vaccinations [63]. Before recommendations of preventive strategies are suggested, it is important to evaluate possible negative effects of such attempts. There are indications of an inverse relation between $H$. pylori infection and risk of esophageal adenocarcinoma, a cancer with a most rapidly increasing incidence, which is one reason to maintain a prudent attitude toward grand-scale vaccination programs $[58,64$, 65]. Furthermore, the issue of antibiotic resistance must be considered [66]. Better sanitation and improved public health has probably led to the observed decline in the prevalence of $H$. pylori infection in the industrialized world.

Fruit and vegetables

There is substantial evidence that a diet rich in fruit and vegetables is protective against gastric cancer [67, 68]. Prospective studies have repeatedly shown significant reductions in the risk of gastric cancer in association with high consumption of fruit and vegetables [69-71]. Findings in numerous case-control studies have also supported this protective effect $[18,72,73]$. Carcinogenic N-nitrosamines can, however, be generated from nitrite. This anion is formed from reduction of nitrate, abundant in many foods. For people who consume a typical Western diet, vegetables account for $60-80 \%$ of the daily intake of nitrate [74]. The highest concentrations of nitrate are present in leafy green vegetables such as salad and spinach, although the nitrate levels in vegetables can vary considerably depending, e.g. on the use of nitrogen fertilizers [75]. Small amounts of nitrite also come from processed meat [74].

\section{Tobacco smoking}

The relation between tobacco smoking and gastric cancer has been the focus of many studies over the years, and taken together these studies indicate that smoking is a moderate risk factor [76]. In a meta-analysis of the relation between smoking and gastric cancer, the excess risk associated with smoking was estimated to be $50-60 \%$ [77]. The relative risk was higher in men $(59 \%)$ than in women $(11 \%)$. If this association is true, the high prevalence of tobacco smoking in the world suggests that a substantial number of gastric cancer cases $(80,000)$ could be due to smoking [77]. A recent systematic review and meta-analysis only considering cohort studies, showed that the risk of gastric cancer is increased by $60 \%$ in male smokers and by $20 \%$ in female smokers, compared to never smokers, and that the associations are weaker in former smokers [78]. A difference in risk depending on the anatomical location of the tumor within the stomach is a possibility. Some prospective studies have indicated that non-cardia gastric cancer is associated with a stronger risk [79], whereas others, e.g., a large prospective study [80], have shown the opposite. There is some evidence of a strongly increased risk among people with CagA-positive $H$. pylori strains who smoke, thus suggesting interaction between these exposures in relation to gastric cancer development [81]. Smoking is a risk factor typically acquired early in life, and some data indicates that earlier onset of smoking is a risk factor per se [82]. It is biologically plausible that that the anti-carcinogenic defence mechanisms more easily become overwhelmed in a younger organism. The same kind of association has been demonstrated regarding smoking and lung cancer [83].

\section{Alcohol}

On the basis of most previous research, alcohol consumption seems to be an unlikely cause of gastric cancer [17, 68, 84-86], although some results are partly contradictory [82, 86, 87].

\section{Obesity}

Although high Body Mass Index (BMI) is linked with an overall increase in the risk of cancer in general, and is an established and strong risk factor for gastric cardia adenocarcinoma [84, 88, 89], results from case-control studies addressing the risk of gastric cancer have rather indicated a link between low BMI and gastric cancer [90- 
93], while prospective studies have yielded contradictory results $[84,89,94-102]$. Taken together, obesity does not seem to play a major role in the etiology of gastric cancer distal to the cardia.

\section{Gastroesophageal reflux}

Cancer of the gastric cardia is positively associated with the exposures gastroesophageal reflux, obesity and tobacco smoking [103]. Obesity and reflux are associated with each other, but both are also independent risk factors of cardia cancer [104].

\section{Physical activity}

Only in a few studies has physical activity been investigated in relation to risk of gastric cancer. One prospective study has shown an increased risk associated with measures of increased activity [105], while others have not shown any association $[106,107]$. A recent prospective cohort study in Norway, on the other hand, indicated that recreational physical activity protects against gastric cancer [101]. Another large prospective study investigating gastric cancer in relation to physical activity in a cohort of US men and women found evidence of a reduced risk, the inverse association with physical activity was strongest for gastric non cardia adenocarcinoma [108]. A biological mechanism linking physical activity to a decreased risk of gastric cancer risk is lacking, but multiple pathways are plausible, e.g. a genetic predisposition of habitually active persons [109], an improved immune function with increases in level and activity of circulating tumor-inhibiting natural killer cells [110], up-regulation of the activity of free scavenger systems and oxidant levels [111, 112], and decreased levels of insulin and insulin-like growth factors [113].

\section{Salt intake}

The hypothesis that high dietary salt intake increases the risk of gastric adenocarcinoma was spawned in the 1960s, and evidence has gained support from ecological, casecontrol and cohort studies, mainly from high-incidence Asian countries, over the past decades [67, 68, 114, 115]. The falling incidence of this malignancy has coincided with the spread of refrigeration, which should be inversely associated with salting and other salt-based methods of food preservation [68]. Salt is thought to increase the risk of gastric adenocarcinoma through induction of chronic inflammation of the gastric mucosa. A high salt concentration in the gastric mucosa could lead to diffuse erosion, and the induced proliferation in the inflamed environment could promote the effect of carcinogens derived from food [22]. However, few prospective studies have assessed the association of salt intake with the risk of gastric adenocarcinoma, particularly in Western societies, and the results from these studies have been inconsistent, thus leaving some doubt about the role of salt in gastric cancer etiology [114]. The authors of a recent review of salt consumption and gastric cancer risk concluded, however, that limitation on salt and salted foods is a practical strategy for preventing gastric cancer [116].

\section{Occupational exposures}

Many studies of gastric cancer have been conducted within occupational settings. There is evidence that occupations in coal and tin mining, metal processing, particularly of steel and iron, and rubber manufacturing industries lead to an increased risk of gastric cancer [117]. Other "dusty" occupations have also been implicated, but the evidence is not strong [118-121]. Most of these investigations have used job titles as a proxy for exposure of specific carcinogenic exposures [117], and there has often been a lack of information regarding potential confounding factors. Therefore, the potential harmful effect of several specific occupational exposures remains uncertain.

\section{Socioeconomic status}

Low socioeconomic status has consistently been shown to be associated with an increased risk of gastric cancer [2, 122], and recent data also supports a similar link with cardia cancer [99, 123]. Socioeconomic status is a potential proxy for a number of factors, e.g. lifestyle patterns, dietary habits, BMI, H. pylori infection and smoking habits [124]. Some researchers also stress the potential influence on disease risk of commercial marketing activities, relative social status, levels of income and education (often used as proxy measures for socioeconomic status), access to the health care system, and the strength or absence of social networks [125]. Following these lines of argument, the environmental factor $H$. pylori which has attracted most attention lately could be viewed as one of the causative agents underlying the statement "poverty is a carcinogen."

\section{Female sex hormones}

The yet unexplained 2-3:1 male predominance in gastric cancer has prompted the hypothesis that premenopausal women are protected from developing gastric adenocarcinoma by virtue of their high endogenous estrogen exposure. The global finding that women develop the intestinal type of gastric adenocarcinoma on average 10-15 years later than men [126], and that the incidence of this type of cancer increases after the menopause, has sparked an interest in further investigations. One prospective study indicated that 
hormone replacement therapy with estrogens is associated with a risk reduction of gastric cancer, particularly of the non-cardia site [127]. Other studies have shown further indications favoring such an association [128]. More research is however needed before such a potential effect is proven.

\section{Other causes}

Prior gastric surgery for benign conditions has been shown to be associated with gastric cancer [129, 130]. Twenty years after gastric resection for a benign disease the relative risk has been found to be increased. The risk of cancer in the gastric remnant ("stump" cancer) can relate to the production of nitrosamines by bacteria in the relatively hypoacidic stomach remnant or as a result of long-term bile damage to the gastric mucosa. However, since peptic ulcer disease is also related to gastric cancer, the relation between gastric surgery for this benign condition and gastric cancer is difficult to establish [131].

There is an excess risk of developing gastric adenocarcinoma in persons with pernicious anemia. This appears to be an autoimmune disease leading to chronic atrophic gastritis type A (type B is represented by $H$. pylori related gastritis) located mainly in the corpus of the stomach [132]. Atrophic gastritis is a stage in Correa's model of gastric carcinogenesis and should be regarded as a premalignant state if found in a patient, even in the absence of $H$. pylori infection.

Epstein-Barr virus may play an etiological role in a subset of gastric adenocarcinomas [133, 134]. This virus is ubiquitous in all human populations, and about $10 \%$ of gastric cancers throughout the world show monoclonal proliferation of Epstein-Barr virus-infected cells [135]. In contrast to Burkitt lymphoma and nasopharyngeal carcinoma, which are endemic in Africa and Southeast Asia, Epstein-Barr-positive gastric cancers are non-endemic and distributed more evenly throughout the world [135]. Lymphoepithelioma-like gastric cancer might be the main, if not the only, gastric cancer positive for Epstein-Barr cancer [136].

A $20 \%$ increase in relative risk of gastric cancer among people with blood group $A$, compared to those with blood group 0, was reported already in 1953 [137]. This difference has been attributed to the nature of mucopolysaccharide secretion in the stomach of blood group A individuals, and to a greater susceptibility to ingested carcinogens.

Follow-up of atomic bomb survivors, exposed to ionizing radiation, has revealed an increased risk of gastric cancer, as well as of cancer at many other sites [96, 138].

Patients with primary immunodeficiency are at increased risk of developing hematological malignancies, and sometimes also carcinoma. The risk of developing chronic atrophic gastritis, metaplasia, and distal cancer seems to be especially pronounced [139].

\section{Prognosis}

Almost two thirds of all cases of gastric cancer occur in the developing world. A diagnosis of gastric cancer in Western countries is brightened with some hope of cure, while in developing countries the diagnosis is almost without exception terminal. However, the prognosis in the Western hemisphere is also disappointing, and the estimated 5-year survival in Western societies is only $24-27 \%$ [2, 140]. There has been only a slight improvement during the past 20 30 years, despite all attempts to improve the survival with, e.g., different surgical techniques and various combinations of chemotherapeutic drugs [141]. The individual prognosis is highly dependent on tumor stage at presentation. In Japan, screening is carried out for gastric cancer, resulting in detection of up to $40 \%$ of these cancers at an early stage with much better prognosis as a result [142]. In Europe, the proportion of early gastric cancer is less than $15 \%$ [142].

\section{Gastric cancer prevention}

Chemoprevention trials of gastric cancer have been attempted with varying success. In a Chinese trial, a reduction in gastric cancer mortality and incidence was found after 5 years in persons who received daily supplementation with beta-carotene, vitamin E, and selenium [143]. A study in a low-risk population of male physicians showed no effect of beta-carotene after an average of 12 years of follow-up [144]. Several studies have shown prevention of the progression of preneoplastic mucosal changes after $H$. pylori eradication and antioxidant supplementation [145-147]. In a recent clinical trial in a high-risk area in Venezuela, supplementation with antioxidant vitamins was not found useful in prevention of gastric precancerous lesions [148]. A trial in a high-incidence area in Colombia studied various interventions on precancerous lesions at baseline. The treatment arms included H. pylori therapy, ascorbic acid supplements, beta-carotene supplements, and all possible combinations of these three interventions. All of these interventions resulted in significant regression of existing premalignant lesions in a pattern not clearly indicating the relative effectiveness of the individual agents [149]. The role of conventional nonsteroidal anti-inflammatory drugs (NSAIDs), cyclooxygenase 2 inhibitors (COX-2), and aspirin as chemopreventive agents remains controversial [150, 151]. In observational studies investigating the relation between these drugs and gastric cancer, confounding by indication is often a serious source of 
bias. However, NSAIDs might exert preventive effects against gastric cancer [152-154]. Unfortunately, no randomized trials with gastric cancer as outcome have yet been completed.

Screening for gastric cancer has been reported to be effective in some populations, but this is not universally accepted [155]. There is currently no biomedical marker of progression of the precancerous process which can reliably be used in screening programs. Screening with pepsinogen serum levels has been suggested as a complement to $H$. pylori antibody titers for high-risk patients [156, 157]. Recent advances related to human cytokine polymorphisms should, in the near future, allow the design and implementation of more targeted, large-scale screening programs aimed at identifying persons at the highest risk of gastric cancer. Interventions may become more specific if genetic polymorphisms are identified with the potential to affect cancer risk in combination with environmental exposures. These are more likely to concern premalignant lesions than invasive cancer.

Some authors consider that a reduction in dietary salt intake, an increase in the consumption of fruit and vegetables, and avoidance of tobacco smoking are effective means to reduce the incidence of gastric cancer [158]. The unplanned prevention that has taken place in the West is probably a result of a better overall socioeconomic standard, leading to a reduced prevalence of H. pylori, and of widespread use of refrigeration, less consumption of salted foods, and increased intake of fresh fruit and vegetables. By elucidating the factors explaining the decline in incidence, this process could potentially be accelerated, making it more effective, e.g., by acting against exposures that counteract this trend. A healthy and active attitude of cancer-epidemiological vigilance should be maintained to ensure maintenance of the falling incidence of gastric cancer.

\section{Concluding remarks}

Tremendous effort has been made to shed light on the causation of gastric cancer. But there is still a need for research aiming to increase our understanding of the etiology of this cancer, facilitating the design of successful targeted preventive strategies for different populations. The future outlook in terms of decreasing gastric cancer deaths would be to identify such intelligent diagnostic tools.

A foreseeable consequence of methodological advances in assessing gene-environment interactions is that people might be characterized according to their inherent cancer susceptibility. The availability of such information would raise ethical issues regarding, e.g., the protection of workers from occupational hazards. This is also a valid argument regarding lifestyle factors in other sections of a population and should be kept in mind when deciding to test for newly identified potentially critical genetic variants. It is conceivable that every person in a population is at much higher risk than most other persons for a specific cancer type, and the question should always be discussed on an individual level before a decision is made to take the test or not. For some people, knowledge can sometimes be a burden and would in retrospect not really have wanted to know that they are at a high risk of developing a disease or that they have attracted a pre-malign condition. The field of genetic epidemiology is rapidly evolving and future research toward an understanding of the etiology and a targeted prevention of gastric cancer will move in the direction of molecular epidemiology to a greater extent.

Acknowledgement This article is partly based on a $\mathrm{PhD}$-thesis by Krister Sjödahl at Karolinska Institutet, Stockholm, Sweden 2008.

Conflict of interest statement No conflicts of interests exist.

\section{References}

1. Parkin DM, Bray F, Ferlay J, Pisani P. Global cancer statistics, 2002. CA Cancer J Clin. 2005;55:74-108.

2. Forman D, Burley VJ. Gastric cancer: global pattern of the disease and an overview of environmental risk factors. Best Pract Res Clin Gastroenterol. 2006;20:633-49.

3. Bertuccio P, Chatenoud L, Levi F, Praud D, Ferlay J, Negri E, et al. Recent patterns in gastric cancer: a global overview. Int $\mathrm{J}$ Cancer. 2009;125:666-73.

4. Murray CJ, Lopez AD. Mortality by cause for eight regions of the world: Global Burden of Disease Study. Lancet. 1997;349:1269-76.

5. Lindblad M, Ye W, Lindgren A, Lagergren J. Disparities in the classification of esophageal and cardia adenocarcinomas and their influence on reported incidence rates. Ann Surg. 2006;243:479-85.

6. Siewert JR, Stein HJ. Classification of adenocarcinoma of the oesophagogastric junction. Br J Surg. 1998;85:1457-9.

7. Blot WJ, Devesa SS, Kneller RW, Fraumeni Jr JF. Rising incidence of adenocarcinoma of the esophagus and gastric cardia. Jama. 1991;265:1287-9.

8. Devesa SS, Blot WJ, Fraumeni Jr JF. Changing patterns in the incidence of esophageal and gastric carcinoma in the United States. Cancer. 1998;83:2049-53.

9. Parkin DM. Global cancer statistics in the year 2000. Lancet Oncol. 2001;2:533-43.

10. Hansson LE, Bergstrom R, Sparen P, Adami HO. The decline in the incidence of stomach cancer in Sweden 1960-1984: a birth cohort phenomenon. Int J Cancer. 1991;47:499-503.

11. Compton C, Sobin LH. Protocol for the examination of specimens removed from patients with gastric carcinoma: a basis for checklists. Members of the Cancer Committee, College of American Pathologists, and the Task Force for Protocols on the Examination of Specimens From Patients With Gastric Cancer. Arch Pathol Lab Med. 1998;122:9-14.

12. Lauren P. The two histological main types of gastric carcinoma: diffuse and so-called intestinal-type carcinoma. An attempt at a 
histo-clinical classification. Acta Pathol Microbiol Scand. 1965;64:31-49.

13. Jarvi O, Lauren P. On the role of heterotopias of the intestinal epithelium in the pathogenesis of gastric cancer. Acta Pathol Microbiol Scand. 1951;29:26-44.

14. Munoz N, Correa P, Cuello C, Duque E. Histologic types of gastric carcinoma in high- and low-risk areas. Int $\mathrm{J}$ Cancer. 1968;3:809-18.

15. Kelley JR, Duggan JM. Gastric cancer epidemiology and risk factors. J Clin Epidemiol. 2003;56:1-9.

16. Boeing H, Jedrychowski W, Wahrendorf J, Popiela T, TobiaszAdamczyk B, Kulig A. Dietary risk factors in intestinal and diffuse types of stomach cancer: a multicenter case-control study in Poland. Cancer Causes Control. 1991;2:227-33.

17. Ye W, Ekstrom AM, Hansson LE, Bergstrom R, Nyren O. Tobacco, alcohol and the risk of gastric cancer by sub-site and histologic type. Int J Cancer. 1999;83:223-9.

18. Ekstrom AM, Serafini M, Nyren O, Hansson LE, Ye W, Wolk A. Dietary antioxidant intake and the risk of cardia cancer and noncardia cancer of the intestinal and diffuse types: a populationbased case-control study in Sweden. Int J Cancer. 2000;87:13340.

19. Hamilton JP, Meltzer SJ. A review of the genomics of gastric cancer. Clin Gastroenterol Hepatol. 2006;4:416-25.

20. Chan AO. E-cadherin in gastric cancer. World J Gastroenterol. 2006;12:199-203.

21. Correa P, Haenszel W, Cuello C, Tannenbaum S, Archer M. A model for gastric cancer epidemiology. Lancet. 1975;2:58-60.

22. Correa P. Human gastric carcinogenesis: a multistep and multifactorial process-First American Cancer Society Award Lecture on Cancer Epidemiology and Prevention. Cancer Res. 1992;52:6735-40.

23. Bartsch H, Ohshima H, Pignatelli B. Inhibitors of endogenous nitrosation. Mechanisms and implications in human cancer prevention. Mutat Res. 1988;202:307-24.

24. Stemmermann GN, Mower H. Gastritis, nitrosamines, and gastric cancer. J Clin Gastroenterol. 1981;3:23-7.

25. Suzuki M, Suzuki H, Hibi T. Proton pump inhibitors and gastritis. J Clin Biochem Nutr. 2008;42:71-5.

26. Poulsen AH, Christensen S, McLaughlin JK, Thomsen RW, Sorensen HT, Olsen JH, et al. Proton pump inhibitors and risk of gastric cancer: a population-based cohort study. $\mathrm{Br} \mathrm{J}$ Cancer. 2009;100:1503-7.

27. Logan RP, Walker MM, Misiewicz JJ, Gummett PA, Karim QN, Baron $\mathrm{JH}$. Changes in the intragastric distribution of Helicobacter pylori during treatment with omeprazole. Gut. 1995;36:12-6.

28. Garcia Rodriguez LA, Lagergren J, Lindblad M. Gastric acid suppression and risk of oesophageal and gastric adenocarcinoma: a nested case control study in the UK. Gut. 2006;55:1538-44.

29. Correa P. Does Helicobacter pylori cause gastric cancer via oxidative stress? Biol Chem. 2006;387:361-4.

30. Correa P. The role of antioxidants in gastric carcinogenesis. Crit Rev Food Sci Nutr. 1995;35:59-64.

31. Houghton J, Stoicov C, Nomura S, Rogers AB, Carlson J, Li H, et al. Gastric cancer originating from bone marrow-derived cells. Science. 2004;306:1568-71.

32. Correa P, Houghton J. Carcinogenesis of Helicobacter pylori. Gastroenterology. 2007;133:659-72.

33. Haenszel W, Kurihara M. Studies of Japanese migrants. I. Mortality from cancer and other diseases among Japanese in the United States. J Natl Cancer Inst. 1968;40:43-68.

34. Hemminki K, Zhang H, Czene K. Socioeconomic factors in cancer in Sweden. Int J Cancer. 2003;105:692-700.

35. Power C, Hypponen E, Smith GD. Socioeconomic position in childhood and early adult life and risk of mortality: a prospective study of the mothers of the 1958 British birth cohort. Am J Public Health. 2005;95:1396-402.

36. Lichtenstein P, Holm NV, Verkasalo PK, Iliadou A, Kaprio J, Koskenvuo M, et al. Environmental and heritable factors in the causation of cancer-analyses of cohorts of twins from Sweden, Denmark, and Finland. N Engl J Med. 2000;343:78-85.

37. Chan AO, Wong BC, Lan HY, Loke SL, Chan WK, Hui WM, et al. Deregulation of E-cadherin-catenin complex in precancerous lesions of gastric adenocarcinoma. J Gastroenterol Hepatol. 2003; 18:534-9.

38. Terres AM, Pajares JM, O'Toole D, Ahern S, Kelleher D. H pylori infection is associated with downregulation of E-cadherin, a molecule involved in epithelial cell adhesion and proliferation control. J Clin Pathol. 1998;51:410-2.

39. Terres AM, Pajares JM, Hopkins AM, Murphy A, Moran A, Baird AW, et al. Helicobacter pylori disrupts epithelial barrier function in a process inhibited by protein kinase $\mathrm{C}$ activators. Infect Immun. 1998;66:2943-50.

40. Crusius JB, Canzian F, Capella G, Pena AS, Pera G, Sala N, et al. Cytokine gene polymorphisms and the risk of adenocarcinoma of the stomach in the European prospective investigation into cancer and nutrition (EPIC-EURGAST). Ann Oncol. 2008;19:1894-902.

41. Kamangar F, Cheng C, Abnet CC, Rabkin CS. Interleukin-1B polymorphisms and gastric cancer risk-a meta-analysis. Cancer Epidemiol Biomark Prev. 2006;15:1920-8.

42. Marshall BJ, Warren JR. Unidentified curved bacilli in the stomach of patients with gastritis and peptic ulceration. Lancet. 1984;1:1311-5.

43. Schistosomes, liver flukes and Helicobacter pylori. IARC Working Group on the Evaluation of Carcinogenic Risks to Humans. Lyon, 7-14 June 1994. IARC Monogr Eval Carcinog Risks Hum, 61: 1-241, 1994.

44. Gastric cancer and Helicobacter pylori: a combined analysis of 12 case control studies nested within prospective cohorts. Gut, 49: 347-53, 2001.

45. Lochhead P, El-Omar EM. Gastric cancer. Br Med Bull. 2008;85:87-100

46. Uemura N, Okamoto S, Yamamoto S, Matsumura N, Yamaguchi S, Yamakido $\mathrm{M}$, et al. Helicobacter pylori infection and the development of gastric cancer. $\mathrm{N}$ Engl $\mathrm{J}$ Med. 2001;345:784-9.

47. Huang JQ, Sridhar S, Chen Y, Hunt RH. Meta-analysis of the relationship between Helicobacter pylori seropositivity and gastric cancer. Gastroenterology. 1998;114:1169-79.

48. Eslick GD, Lim LL, Byles JE, Xia HH, Talley NJ. Association of Helicobacter pylori infection with gastric carcinoma: a metaanalysis. Am J Gastroenterol. 1999;94:2373-9.

49. Danesh J. Helicobacter pylori infection and gastric cancer: systematic review of the epidemiological studies. Aliment Pharmacol Ther. 1999;13:851-6.

50. Kivi M, Tindberg Y. Helicobacter pylori occurrence and transmission: a family affair? Scand J Infect Dis. 2006;38:407-17.

51. Kusters JG, van Vliet AH, Kuipers EJ. Pathogenesis of Helicobacter pylori infection. Clin Microbiol Rev. 2006;19:449-90.

52. Malaty HM. Epidemiology of Helicobacter pylori infection. Best Pract Res Clin Gastroenterol. 2007;21:205-14.

53. Eslick GD. Helicobacter pylori infection causes gastric cancer? A review of the epidemiological, meta-analytic, and experimental evidence. World J Gastroenterol. 2006;12:2991-9.

54. Lunet N, Barros H. Helicobacter pylori infection and gastric cancer: facing the enigmas. Int J Cancer. 2003;106:953-60.

55. Crew KD, Neugut AI. Epidemiology of gastric cancer. World J Gastroenterol. 2006;12:354-62.

56. Hatakeyama M. Helicobacter pylori CagA - a bacterial intruder conspiring gastric carcinogenesis. Int J Cancer. 2006;119:1217-23. 
57. Ekstrom AM, Held M, Hansson LE, Engstrand L, Nyren O. Helicobacter pylori in gastric cancer established by CagA immunoblot as a marker of past infection. Gastroenterology. 2001;121:784-91.

58. Nyren O, Blot WJ. Helicobacter pylori infection: mainly foe but also friend? J Natl Cancer Inst. 2006;98:1432-4.

59. El-Omar EM, Rabkin CS, Gammon MD, Vaughan TL, Risch HA, Schoenberg JB, et al. Increased risk of noncardia gastric cancer associated with proinflammatory cytokine gene polymorphisms. Gastroenterology. 2003;124:1193-201.

60. Sgouros SN, Bergele C. Clinical outcome of patients with Helicobacter pylori infection: the bug, the host, or the environment? Postgrad Med J. 2006;82:338-42.

61. Graham DY, Yamaoka Y. Disease-specific Helicobacter pylori virulence factors: the unfulfilled promise. Helicobacter. 2000;5 Suppl 1:S3-9. discussion S27-31.

62. Fukase K, Kato M, Kikuchi S, Inoue K, Uemura N, Okamoto S, et al. Effect of eradication of Helicobacter pylori on incidence of metachronous gastric carcinoma after endoscopic resection of early gastric cancer: an open-label, randomised controlled trial. Lancet. 2008;372:392-7.

63. Svennerholm AM, Lundgren A. Progress in vaccine development against Helicobacter pylori. FEMS Immunol Med Microbiol. 2007;50:146-56.

64. Rokkas T, Pistiolas D, Sechopoulos P, Robotis I, Margantinis G. Relationship between Helicobacter pylori infection and esophageal neoplasia: a meta-analysis. Clin Gastroenterol Hepatol. 2007;5:1413-7. 1417 e1-2.

65. Hansen S, Vollset SE, Derakhshan MH, Fyfe V, Melby KK, Aase $\mathrm{S}$, et al. Two distinct aetiologies of cardia cancer; evidence from premorbid serological markers of gastric atrophy and Helicobacter pylori status. Gut. 2007;56:918-25.

66. Vakil N, Megraud F. Eradication therapy for Helicobacter pylori. Gastroenterology. 2007;133:985-1001.

67. Kono S, Hirohata T. Nutrition and stomach cancer. Cancer Causes Control. 1996;7:41-55.

68. World Cancer Research Fund/American Institute for Cancer Research. Food, Nutrition, Physical Activity and the Prevention of Cancer: a Global Perspective. Washington DC: AICR; 2007.

69. McCullough ML, Robertson AS, Jacobs EJ, Chao A, Calle EE, Thun MJ. A prospective study of diet and stomach cancer mortality in United States men and women. Cancer Epidemiol Biomarkers Prev. 2001;10:1201-5.

70. Hertog MG, Bueno-de-Mesquita HB, Fehily AM, Sweetnam PM, Elwood PC, Kromhout D. Fruit and vegetable consumption and cancer mortality in the Caerphilly Study. Cancer Epidemiol Biomarkers Prev. 1996;5:673-7.

71. Kobayashi M, Tsubono Y, Sasazuki S, Sasaki S, Tsugane S. Vegetables, fruit and risk of gastric cancer in Japan: a 10-year follow-up of the JPHC Study Cohort I. Int J Cancer. 2002;102:39-44.

72. Hansson LE, Nyren O, Bergstrom R, Wolk A, Lindgren A, Baron J, et al. Nutrients and gastric cancer risk. A populationbased case-control study in Sweden. Int J Cancer. 1994;57:63844.

73. Serafini M, Bellocco R, Wolk A, Ekstrom AM. Total antioxidant potential of fruit and vegetables and risk of gastric cancer. Gastroenterology. 2002;123:985-91.

74. Speijers, and Brandt. Nitrate (and Potential Endogenous Formation of N-Nitroso Compounds). WHO Food Additives Series: 50: WHO, 2003.

75. McKnight GM, Duncan CW, Leifert C, Golden MH. Dietary nitrate in man: friend or foe? Br J Nutr. 1999;81:349-58.

76. IARC. Tobacco smoking and tobacco smoke. In IARC monographs on evaluation of carcinogenic risks to humans. Lyon: International Agency for Research on Cancer; 2002.
77. Tredaniel J, Boffetta P, Buiatti E, Saracci R, Hirsch A. Tobacco smoking and gastric cancer: review and meta-analysis. Int $\mathrm{J}$ Cancer. 1997;72:565-73.

78. Ladeiras-Lopes R, Pereira AK, Nogueira A, Pinheiro-Torres T, Pinto I, Santos-Pereira R, and Lunet N. Smoking and gastric cancer: systematic review and meta-analysis of cohort studies. Cancer Causes Control. 2008.

79. Koizumi Y, Tsubono Y, Nakaya N, Kuriyama S, Shibuya D, Matsuoka $\mathrm{H}$, et al. Cigarette smoking and the risk of gastric cancer: a pooled analysis of two prospective studies in Japan. Int J Cancer. 2004;112:1049-55.

80. Gonzalez CA, Pera G, Agudo A, Palli D, Krogh V, Vineis P, et al. Smoking and the risk of gastric cancer in the European Prospective Investigation Into Cancer and Nutrition (EPIC). Int J Cancer. 2003;107:629-34.

81. Brenner H, Arndt V, Bode G, Stegmaier C, Ziegler H, Stumer T. Risk of gastric cancer among smokers infected with Helicobacter pylori. Int J Cancer. 2002;98:446-9.

82. Sjodahl K, Lu Y, Nilsen TI, Ye W, Hveem K, Vatten L, et al. Smoking and alcohol drinking in relation to risk of gastric cancer: a population-based, prospective cohort study. Int J Cancer. 2007;120:128-32.

83. Tyczynski JE, Bray F, Parkin DM. Lung cancer in Europe in 2000: epidemiology, prevention, and early detection. Lancet Oncol. 2003;4:45-55.

84. Lindblad M, Rodriguez LA, Lagergren J. Body mass, tobacco and alcohol and risk of esophageal, gastric cardia, and gastric non-cardia adenocarcinoma among men and women in a nested case-control study. Cancer Causes Control. 2005;16:285-94.

85. Lagergren J, Bergstrom R, Lindgren A, Nyren O. The role of tobacco, snuff and alcohol use in the aetiology of cancer of the oesophagus and gastric cardia. Int J Cancer. 2000;85:340-6.

86. Shimazu T, Tsuji I, Inoue M, Wakai K, Nagata C, Mizoue T, et al. Alcohol drinking and gastric cancer risk: an evaluation based on a systematic review of epidemiologic evidence among the Japanese population. Jpn J Clin Oncol. 2008;38:8-25.

87. Gammon MD, Schoenberg JB, Ahsan H, Risch HA, Vaughan TL, Chow WH, et al. Tobacco, alcohol, and socioeconomic status and adenocarcinomas of the esophagus and gastric cardia. J Natl Cancer Inst. 1997;89:1277-84.

88. Chow WH, Blot WJ, Vaughan TL, Risch HA, Gammon MD, Stanford JL, et al. Body mass index and risk of adenocarcinomas of the esophagus and gastric cardia. J Natl Cancer Inst. 1998; $90: 150-5$.

89. Lagergren J, Bergstrom R, Adami HO, Nyren O. Association between medications that relax the lower esophageal sphincter and risk for esophageal adenocarcinoma. Ann Intern Med. 2000;133:165-75.

90. De Stefani E, Correa P, Boffetta P, Deneo-Pellegrini H, Ronco $\mathrm{AL}$, Mendilaharsu M. Dietary patterns and risk of gastric cancer: a case-control study in Uruguay. Gastric Cancer. 2004;7:211-20.

91. Munoz N, Plummer M, Vivas J, Moreno V, De Sanjose S, Lopez $\mathrm{G}$, et al. A case-control study of gastric cancer in Venezuela. Int J Cancer. 2001;93:417-23.

92. Huang XE, Tajima K, Hamajima N, Xiang J, Inoue M, Hirose K, et al. Comparison of lifestyle and risk factors among Japanese with and without gastric cancer family history. Int $\mathrm{J}$ Cancer. 2000;86:421-4.

93. Inoue M, Ito LS, Tajima K, Yamamura Y, Kodera Y, Takezaki T, et al. Height, weight, menstrual and reproductive factors and risk of gastric cancer among Japanese postmenopausal women: analysis by subsite and histologic subtype. Int $\mathrm{J}$ Cancer. 2002;97:833-8.

94. Kuriyama S, Tsubono Y, Hozawa A, Shimazu T, Suzuki Y, Koizumi $\mathrm{Y}$, et al. Obesity and risk of cancer in Japan. Int $\mathbf{J}$ Cancer. 2005;113:148-57. 
95. Lukanova A, Bjor O, Kaaks R, Lenner P, Lindahl B, Hallmans G, et al. Body mass index and cancer: results from the Northern Sweden Health and Disease Cohort. Int J Cancer. 2006;118:458-66.

96. Sauvaget C, Lagarde F, Nagano J, Soda M, Koyama K, Kodama $\mathrm{K}$. Lifestyle factors, radiation and gastric cancer in atomic-bomb survivors (Japan). Cancer Causes Control. 2005;16:773-80.

97. Wolk A, Gridley G, Svensson M, Nyren O, McLaughlin JK, Fraumeni JF, et al. A prospective study of obesity and cancer risk (Sweden). Cancer Causes Control. 2001;12:13-21.

98. Zhang J, Su XQ, Wu XJ, Liu YH, Wang H, Zong XN, et al. Effect of body mass index on adenocarcinoma of gastric cardia. World J Gastroenterol. 2003;9:2658-61.

99. Tran GD, Sun XD, Abnet CC, Fan JH, Dawsey SM, Dong ZW, et al. Prospective study of risk factors for esophageal and gastric cancers in the Linxian general population trial cohort in China. Int J Cancer. 2005;113:456-63.

100. Tulinius H, Sigfusson N, Sigvaldason H, Bjarnadottir K, Tryggvadottir L. Risk factors for malignant diseases: a cohort study on a population of 22, 946 Icelanders. Cancer Epidemiol Biomarkers Prev. 1997;6:863-73.

101. Sjodahl K, Jia C, Vatten L, Nilsen T, Hveem K, Lagergren J. Body mass and physical activity and risk of gastric cancer in a population-based cohort study in norway. Cancer Epidemiol Biomarkers Prev. 2008;17:135-40.

102. Abnet CC, Freedman ND, Hollenbeck AR, Fraumeni Jr JF, Leitzmann M, Schatzkin A. A prospective study of BMI and risk of oesophageal and gastric adenocarcinoma. Eur $\mathrm{J}$ Cancer. 2008:44:465-71.

103. McColl KE. Cancer of the gastric cardia. Best Pract Res Clin Gastroenterol. 2006;20:687-96.

104. Lagergren J, Bergstrom R, Lindgren A, Nyren O. Symptomatic gastroesophageal reflux as a risk factor for esophageal adenocarcinoma. N Engl J Med. 1999;340:825-31.

105. Severson RK, Nomura AM, Grove JS, Stemmermann GN. A prospective analysis of physical activity and cancer. Am J Epidemiol. 1989;130:522-9.

106. Wannamethee SG, Shaper AG, Walker M. Physical activity and risk of cancer in middle-aged men. Br J Cancer. 2001;85:1311-6.

107. Davey Smith G, Shipley MJ, Batty GD, Morris JN, M Marmot. Physical activity and cause-specific mortality in the Whitehall study. Public Health. 2000;114:308-15.

108. Leitzmann MF, Koebnick C, Freedman ND, Park Y, BallardBarbash R, Hollenbeck A, et al. Physical activity and esophageal and gastric carcinoma in a large prospective study. Am J Prev Med. 2009;36:112-9.

109. Friedenreich CM. Physical activity and cancer prevention: from observational to intervention research. Cancer Epidemiol Biomarkers Prev. 2001;10:287-301.

110. Friedenreich CM, Orenstein MR. Physical activity and cancer prevention: etiologic evidence and biological mechanisms. J Nutr. 2002;132:3456S-64.

111. Chang CK, Tseng HF, Hsuuw YD, Chan WH, Shieh LC. Higher LDL oxidation at rest and after a rugby game in weekend warriors. Ann Nutr Metab. 2002;46:103-7.

112. Finaud J, Lac G, Filaire E. Oxidative stress: relationship with exercise and training. Sports Med. 2006;36:327-58.

113. Yu H, Rohan T. Role of the insulin-like growth factor family in cancer development and progression. J Natl Cancer Inst. 2000;92:1472-89.

114. Tsugane S, Sasazuki S. Diet and the risk of gastric cancer: review of epidemiological evidence. Gastric Cancer. 2007;10:75-83.

115. Joossens JV, Hill MJ, Elliott P, Stamler R, Lesaffre E, Dyer A, et al. Dietary salt, nitrate and stomach cancer mortality in 24 countries. European Cancer Prevention (ECP) and the INTERSALT Cooperative Research Group. Int J Epidemiol. 1996;25:494-504.
116. Wang XQ, Terry PD, Yan H. Review of salt consumption and stomach cancer risk: epidemiological and biological evidence. World J Gastroenterol. 2009;15:2204-13.

117. Raj A, Mayberry JF, Podas T. Occupation and gastric cancer. Postgrad Med J. 2003;79:252-8.

118. Coggon D, Barker DJ, Cole RB. Stomach cancer and work in dusty industries. Br J Ind Med. 1990;47:298-301.

119. Cocco P, Ward MH, Buiatti E. Occupational risk factors for gastric cancer: an overview. Epidemiol Rev. 1996;18:218-34.

120. Aragones N, Pollan M, Gustavsson P. Stomach cancer and occupation in Sweden: 1971-89. Occup Environ Med. 2002;59:329-37.

121. Sjodahl K, Jansson C, Bergdahl IA, Adami J, Boffetta P, Lagergren J. Airborne exposures and risk of gastric cancer: a prospective cohort study. Int J Cancer. 2007;120:2013-8.

122. Hansson LE, Baron J, Nyren O, Bergstrom R, Wolk A, Lindgren A, et al. Early-life risk indicators of gastric cancer. A populationbased case-control study in Sweden. Int J Cancer. 1994;57:32-7.

123. Nagel G, Linseisen J, Boshuizen HC, Pera G, Del Giudice G, Westert GP, et al. Socioeconomic position and the risk of gastric and oesophageal cancer in the European Prospective Investigation into Cancer and Nutrition (EPIC-EURGAST). Int $\mathrm{J}$ Epidemiol. 2007;36:66-76.

124. Isaacs SL, Schroeder SA. Class - the ignored determinant of the nation's health. N Engl J Med. 2004;351:1137-42.

125. Hiatt RA. The social determinants of cancer. Eur J Epidemiol. 2004;19:821-2.

126. Sipponen P, Correa P. Delayed rise in incidence of gastric cancer in females results in unique sex ratio $(\mathrm{M} / \mathrm{F})$ pattern: etiologic hypothesis. Gastric Cancer. 2002;5:213-9.

127. Lindblad M, Garcia Rodriguez LA, Chandanos E, Lagergren J. Hormone replacement therapy and risks of oesophageal and gastric adenocarcinomas. Br J Cancer. 2006;94:136-41.

128. Chandanos E, Lindblad M, Rubio CA, Jia C, Warner M, Gustafsson JK and Lagergren J. Tamoxifen exposure in relation to gastric adenocarcinoma development. Eur J Cancer. 2008.

129. Stalnikowicz R, Benbassat J. Risk of gastric cancer after gastric surgery for benign disorders. Arch Intern Med. 1990;150:20226.

130. Moller H, Toftgaard C. Cancer occurrence in a cohort of patients surgically treated for peptic ulcer. Gut. 1991;32:740-4.

131. Hansson LE. Risk of stomach cancer in patients with peptic ulcer disease. World J Surg. 2000;24:315-20.

132. Hsing AW, Hansson LE, McLaughlin JK, Nyren O, Blot WJ, Ekbom A, et al. A population-based cohort study. Pernicious anemia and subsequent cancer. Cancer. 1993;71:745-50.

133. Levine PH, Stemmermann G, Lennette ET, Hildesheim A, Shibata D, Nomura A. Elevated antibody titers to Epstein-Barr virus prior to the diagnosis of Epstein-Barr-virus-associated gastric adenocarcinoma. Int J Cancer. 1995;60:642-4.

134. Uemura Y, Tokunaga M, Arikawa J, Yamamoto N, Hamasaki Y, Tanaka S, et al. A unique morphology of Epstein-Barr virusrelated early gastric carcinoma. Cancer Epidemiol Biomarkers Prev. 1994;3:607-11.

135. Takada K. Epstein-Barr virus and gastric carcinoma. Mol Pathol. 2000;53:255-61.

136. Shousha S, Luqmani YA. Epstein-Barr virus in gastric carcinoma and adjacent normal gastric and duodenal mucosa. J Clin Pathol. 1994:47:695-8.

137. Aird I, Bentall HH, Roberts JA. A relationship between cancer of stomach and the ABO blood groups. Br Med J. 1953;1:799-801.

138. Thompson DE, Mabuchi K, Ron E, Soda M, Tokunaga M, Ochikubo S, et al. Cancer incidence in atomic bomb survivors. Part II: Solid tumors, 1958-1987. Radiat Res. 1994;137:S17-67.

139. Paller AS. Immunodeficiency syndromes. X-linked agammaglobulinemia, common variable immunodeficiency, Chediak- 
Higashi syndrome, Wiskott-Aldrich syndrome, and X-linked lymphoproliferative disorder. Dermatol Clin. 1995;13:65-71.

140. Parkin DM. The global health burden of infection-associated cancers in the year 2002. Int J Cancer. 2006;118:3030-44.

141. Hansson LE, Ekstrom AM, Bergstrom R, Nyren O. Surgery for stomach cancer in a defined Swedish population: current practices and operative results. Swedish Gastric Cancer Study Group. Eur J Surg. 2000;166:787-95.

142. Hohenberger P, Gretschel S. Gastric cancer. Lancet. 2003;362:305-15.

143. Blot WJ, Li JY, Taylor PR, Guo W, Dawsey SM, Li B. The Linxian trials: mortality rates by vitamin-mineral intervention group. Am J Clin Nutr. 1995;62:1424S-6.

144. Hennekens CH, Buring JE, Manson JE, Stampfer M, Rosner B, Cook NR, et al. Lack of effect of long-term supplementation with beta carotene on the incidence of malignant neoplasms and cardiovascular disease. N Engl J Med. 1996;334:1145-9.

145. Sung JJ, Lin SR, Ching JY, Zhou LY, To KF, Wang RT, et al. Atrophy and intestinal metaplasia one year after cure of $\mathrm{H}$. pylori infection: a prospective, randomized study. Gastroenterology. 2000;119:7-14.

146. Wong BC, Lam SK, Wong WM, Chen JS, Zheng TT, Feng RE, et al. Helicobacter pylori eradication to prevent gastric cancer in a high-risk region of China: a randomized controlled trial. Jama. 2004;291:187-94.

147. Ley C, Mohar A, Guarner J, Herrera-Goepfert R, Figueroa LS, Halperin D, et al. Helicobacter pylori eradication and gastric preneoplastic conditions: a randomized, double-blind, placebocontrolled trial. Cancer Epidemiol Biomarkers Prev. 2004;13:410.

148. Plummer M, Vivas J, Lopez G, Bravo JC, Peraza S, Carillo E, et al. Chemoprevention of precancerous gastric lesions with antioxidant vitamin supplementation: a randomized trial in a high-risk population. J Natl Cancer Inst. 2007;99:137-46.
149. Correa P, Fontham ET, Bravo JC, Bravo LE, Ruiz B, Zarama G, et al. Chemoprevention of gastric dysplasia: randomized trial of antioxidant supplements and anti-helicobacter pylori therapy. J Natl Cancer Inst. 2000;92:1881-8.

150. Grau MV, Rees JR, Baron JA. Chemoprevention in gastrointestinal cancers: current status. Basic Clin Pharmacol Toxicol. 2006;98:281-7.

151. Cuzick J, Otto F, Baron JA, Brown PH, Burn J, Greenwald P, et al. Aspirin and non-steroidal anti-inflammatory drugs for cancer prevention: an international consensus statement. Lancet Oncol. 2009;10:501-7.

152. Wang WH, Huang JQ, Zheng GF, Lam SK, Karlberg J, Wong BC. Non-steroidal anti-inflammatory drug use and the risk of gastric cancer: a systematic review and meta-analysis. J Natl Cancer Inst. 2003;95:1784-91.

153. Abnet CC, Freedman ND, Kamangar F, Leitzmann MF, Hollenbeck AR, Schatzkin A. Non-steroidal anti-inflammatory drugs and risk of gastric and oesophageal adenocarcinomas: results from a cohort study and a meta-analysis. $\mathrm{Br} \mathrm{J}$ Cancer. 2009;100:551-7.

154. Epplein M, Nomura AM, Wilkens LR, Henderson BE, Kolonel LN. Nonsteroidal antiinflammatory drugs and risk of gastric adenocarcinoma: the multiethnic cohort study. Am J Epidemiol. 2009;170:507-14.

155. Tan YK, Fielding JW. Early diagnosis of early gastric cancer. Eur J Gastroenterol Hepatol. 2006;18:821-9.

156. Miki K. Gastric cancer screening using the serum pepsinogen test method. Gastric Cancer. 2006;9:245-53.

157. Kang JM, Kim N, Yoo JY, Park YS, Lee DH, Kim HY, et al. The role of serum pepsinogen and gastrin test for the detection of gastric cancer in Korea. Helicobacter. 2008;13:146-56.

158. Fock KM, Talley N, Moayyedi P, Hunt R, Azuma T, Sugano K, et al. Asia-Pacific consensus guidelines on gastric cancer prevention. J Gastroenterol Hepatol. 2008;23:351-65. 